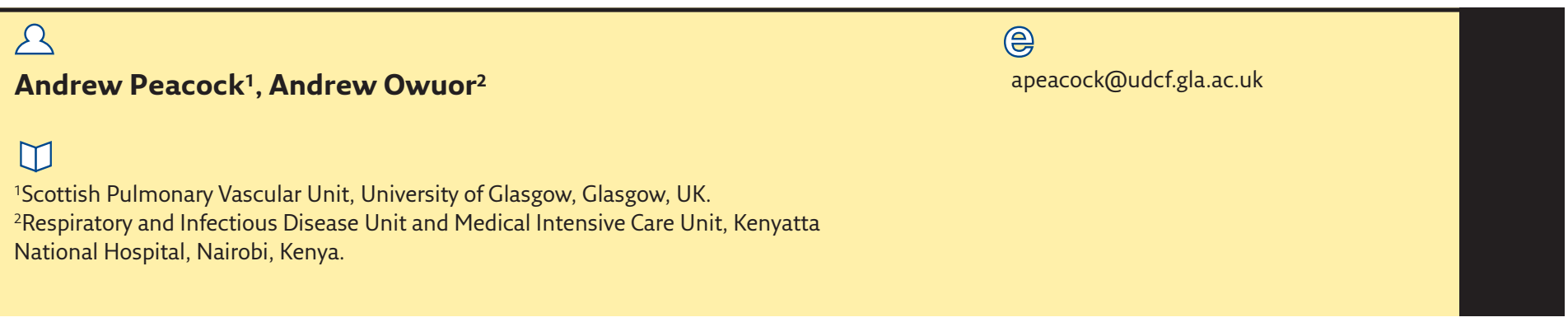

\title{
Pulmonary hypertension and pulmonary vascular disease: course report
}

\section{Course organisers}

A. Peacock, S. Gaine, R. Naeije

\section{Faculty}

M. D’Alto, P. Dorfmüller, S. Gaine, M. Johnson,

S. Konstantinides, B. Lamia, R. Naeije,

A. Peacock, J.Pepke-Zaba, M. Sproule,

A. Vonk Noordegraaf, P. Yerly

This course, held in June 2017, was the fourth course to be organised by the ERS to teach the basics of pulmonary vascular disease and pulmonary hypertension to participants with good knowledge of respiratory medicine, but only a background understanding of pulmonary vascular disease. The first course was held in Edinburgh, UK, in 2007, but since then it has been held in Lausanne at CHUV hospital on a biannual basis in June. Holding the course in a hospital allows access to patients and to equipment such as echocardiography, which ensures that workshops can be conducted live on real patients.

The 2-day course was spread across 3 days, with participants arriving on the Thursday morning and the course running over Thursday afternoon, the whole of Friday and Saturday morning. There were lectures from world-renowned experts in pulmonary vascular disease and seminars and workshops organised by the same experts allowing participants to see how experts perform echocardiography, exercise testing and right heart catheterisation in patients with suspected pulmonary vascular disease.

The course was set up for doctors and senior specialist nurses who already have training in respiratory medicine or cardiology and some understanding of pulmonary vascular disease, especially a familiarity with the problems of pulmonary embolism. At the end of the course the participants should be able to: 1) recognise pulmonary hypertension and make a confident diagnosis of the cause; and 2) initiate appropriate investigations and order appropriate treatment, often with the help of the local specialist centre.

The course was fully funded for 60 participants from 30 countries around the world.

The course provided participants with an introduction to the clinical features, pathophysiology, pathology and pathobiology of pulmonary vascular disease. A new feature this year was special lectures and demonstrations of the right ventricular consequences of pulmonary hypertension and pulmonary hypertension as a consequence of congenital heart disease. An understanding of the heart is important because the heart may be a novel avenue of treatment in the future.

To go with these lectures and demonstrations there were talks on right ventricular imaging by
Cite as: Peacock A, Owuor A. Pulmonary hypertension and pulmonary vascular disease: course report. Breathe 2018; 14: e4-e5. 


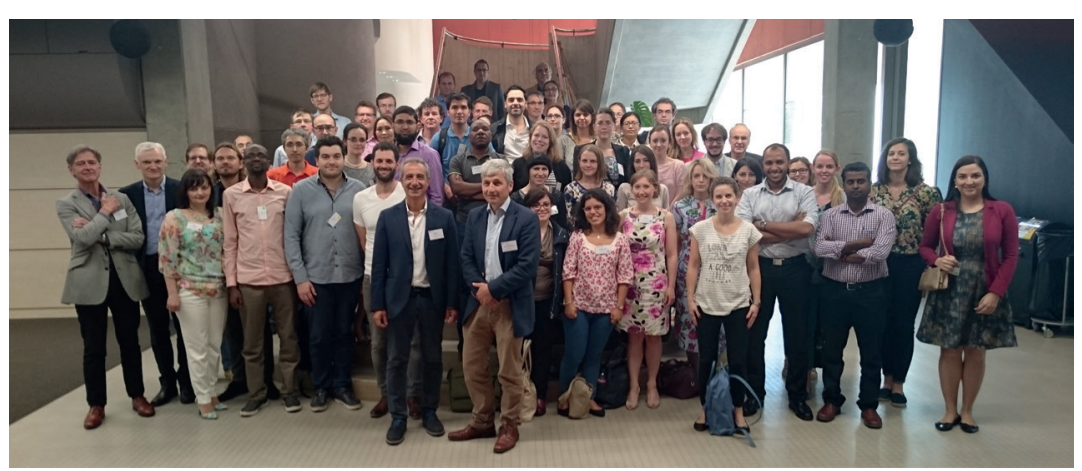

echocardiography and cardiovascular magnetic resonance, right heart catheterisation and cardiopulmonary exercise testing in the context of pulmonary vascular disease. A particularly popular part of the course, because it was within everyone's medical experience, was an in-depth description of the epidemiology, presenting features, consequences and treatment of pulmonary embolism (both acute and chronic).

Another popular innovation was the sessions of interactive case histories. The case histories were mostly provided by the participants themselves so there was lively discussion after each one.

On the final day, we dealt with treatment particularly of idiopathic pulmonary hypertension, but also discussed what to do with patients with left heart disease or hypoxic disease who also have pulmonary hypertension. We finished with a speculative talk on the future of treatment for pulmonary hypertension. Enormous progress has been made, but we can never rest until we can offer a cure.

We finished at lunchtime on the Saturday and we hope that the combination of lectures, case discussions and workshops together with the written course materials left participants with new understanding of, and enthusiasm for, the study of the pulmonary circulation and the right heart.

\section{Andrew Owuor, Kenya, a participant}

The multi- and cross-cultural interactions with participants and faculty from different countries during the course were a fantastic experience as I made new acquaintances and friends from different backgrounds. I also learnt about pulmonary vascular disorders in depth from the highly experienced and competent faculty at our disposal. The atmosphere at the course in Lausanne was warm and the sessions were very academic and at the same time practical. The evening outings for dinner were the highlight of the day after long highly intellectual sessions, as they were full of camaraderie.

During the course, controversies arose among participants on the use of drugs for pulmonary arterial hypertension and pulmonary hypertension secondary to other system disorders. The understanding of the pathophysiology of these entities differs.

From this course, I learnt that chronic pulmonary thromboembolism is actually a disease that contains chronic thromboembolic pulmonary hypertension. In addition, the session on management of patients with pulmonary hypertension in the intensive care unit was quite enlightening.

\section{Next course}

The next course will take place from May 31 to June 2, 2018 at CHUV Lausanne, Switzerland.

\section{Conflict of interest}

Disclosures can be found alongside this article at breathe.ersjournals.com 